\title{
Sexual Responsivity and the Effects of Negative Mood on Sexual Arousal in Hypersexual Men Who Have Sex With Men (MSM)
}

\author{
Erick Janssen, $\mathrm{PhD},{ }^{1,2}$ Nicole Prause, $\mathrm{PhD},{ }^{3}$ Rebecca Swinburne Romine, $\mathrm{PhD},{ }^{4}$ Nancy Raymond, $\mathrm{MD}^{5}$ \\ Angus MacDonald III, $\mathrm{PhD}^{6}$ Eli Coleman, $\mathrm{PhD}^{7}$ and Michael H. Miner, $\mathrm{PhD}^{7}$
}

\begin{abstract}
Background: A number of studies have found that hypersexuality is associated with a high propensity for sexual excitation. In comparison, less is known about the relationship between hypersexuality and sexual arousal at the state level. Also, previous research has revealed a relationship between hypersexuality and negative mood. However, the possibility that sexual response might not be as negatively impacted by negative mood in hypersexual individuals has, as yet, not been tested.
\end{abstract}

Aim: The purpose of this study was to investigate sexual responsivity and the effects of negative mood on sexual arousal in hypersexual men who have sex with men (MSM).

Methods: A total of 211 MSM were assigned to a hypersexuality $(\mathrm{N}=81)$ or a control $(\mathrm{N}=130)$ group using an interview patterned with a semi-structured Structured Clinical Interview for Diagnostic and Statistical Manual of Mental Disorders format. Participants filled out questionnaires and were shown neutral, sexual, and anxietyand sadness-inducing films.

Outcomes: Changes in penile circumference and self-reported sexual arousal were the primary outcomes analyzed in this study.

Results: Controlling for age and HIV status, no differences were found in genital response between hypersexual and non-hypersexual men. Also, the 2 groups did not differ in subjective sexual arousal. Moreover, no effects of negative mood were found. Time series clustering analyses revealed 3 groups- - low responders and slow and fast high responders. Sexual excitation, but not sexual compulsivity or pornography use, predicted cluster membership.

Clinical Translation: Hypersexual MSM may benefit more from an exploration of motivational and behavioral, as compared to psychophysiological, mechanisms underlying possible links between (negative) mood and sexual behavior.

Strengths \& Limitations: Strengths of the study include its sample size, making it one of the larger psychophysiological sex studies; the use of clinical interviews for group assignment; the inclusion of genital response measures; and the application of time series clustering to examine differences among participants. Limitations include possible sample heterogeneity and the reliance on researcher-selected stimuli.

Conclusion: Given the lack of any effects of negative mood on sexual response in hypersexual MSM, future studies could explore in more depth possible motivational and behavioral effects, including, for example, the impact of negative mood on the tendency to seek out sex as a form of distraction or for validation or emotional support. Janssen E, Prause N, Romine RS, et al. Sexual Responsivity and the Effects of Negative Mood on Sexual Arousal in Hypersexual Men Who Have Sex With Men (MSM). J Sex Med 2020;XX:XXX-XXX.

Copyright (C) 2020, International Society for Sexual Medicine. Published by Elsevier Inc. All rights reserved.

Key Words: Hypersexuality; Negative Mood; Sexual Arousal; Psychophysiology; MSM

Received December 28, 2019. Accepted May 5, 2020.

Institute for Family and Sexuality Studies, Department of Neurosciences, University of Leuven, Leuven, Belgium;

${ }^{2}$ Kinsey Institute, Indiana University, IN, USA;

'3iberos, Los Angeles, CA, USA;

${ }^{4}$ The Schiefelbusch Institute for Life Span Studies, University of Kansas, Lawrence, KS, USA;

${ }^{5}$ Department of Psychiatry, University of Wisconsin, Madison, WI, USA;
${ }^{6}$ Department of Psychology, University of Minnesota, Minneapolis, MN, USA;

${ }^{7}$ Department of Family Medicine and Community Health, University of Minnesota, Minneapolis, MN, USA

Copyright ( 2020 , International Society for Sexual Medicine. Published by Elsevier Inc. All rights reserved.

https://doi.org/10.1016/j.jsxm.2020.05.005 


\section{INTRODUCTION}

The scientific literature on hypersexuality—and related constructs such as compulsive sexual behavior, sexual impulsivity, and sex addiction-has grown substantially over the past 2 decades. Yet, the range of experiences and behaviors this term refers to, as well as their possible causes and determinants, remain poorly understood and, in many respects, are a source of controversy. Although there seems little disagreement about the possibility that an individual can feel "out of control" sexually, the debate about whether or not such experiences should be considered pathological and warrant a clinical diagnosis continues. This state of affairs is reflected in the fact that although the recently released edition of International Classification of Diseases- $11^{1}$ recognizes the diagnosis of "compulsive sexual behavior disorder," the Diagnostic and Statistical Manual of Mental Disorders (DSM) $-5^{2}$ has no equivalent, as the proposal to include "hypersexual disorder" was rejected. ${ }^{3}$

Even if the notion of hypersexuality as a disorder was established, the challenge of nomenclature and diagnostic criteria would be compounded by our limited understanding of its causes and determinants. Different terminologies are associated with different assumptions about underlying mechanisms (eg, addiction, compulsivity, impulsivity). ${ }^{4-6}$ In addition, the relative weight of the subjective experience of not feeling in control (and the distress associated with it) vs actual behaviors (and when to consider them to be excessive) further complicates matters. Also, the literature on both the prevalence and possible causes of hypersexuality seems to focus on different behaviors, depending on, among other factors, the sexual orientation of the participants. In heterosexual men and women, a substantial number of studies focus on pornography use, including its correlates and outcomes (eg, on relationships, sexual function). ${ }^{7-10}$ Whereas almost no research exists on the experiences of bisexual and lesbian women, a large proportion of studies in men who have sex with men (MSM) examines hypersexuality in the context of sex with others and its potential for associated risks (eg, sexually transmitted diseases/HIV). ${ }^{1-13}$ Studies also exist that do not make such distinctions and include men and women of different sexual orientations and focus on both high levels of pornography use and high numbers of sexual partners. ${ }^{14-18}$ This is consistent with the fact that most questionnaires that are used to assess out-ofcontrol sexuality-more than 17 have been described in the literature ${ }^{19}$ - do not differentiate between different types of behaviors or problem areas. It remains to be established, however, whether problems involving high levels of pornography use and those involving high levels of partnered sex are associated with similar etiologies, trajectories, and outcomes.

One factor that has been consistently found to be positively associated with hypersexuality, regardless of sexual orientation or gender, is sexual excitation - the ease with which an individual becomes sexually aroused. ${ }^{4,15,20-24}$ This well-replicated finding has played a role in discussions about whether hypersexuality should be considered part of a desire continuum, "a means of satisfying a strong sexual appetite", ${ }^{20}$ and it has contributed to the observation that hypersexual individuals may be "neurologically and behaviorally predisposed to react sexually to specific cues/triggers which they feel unable to control”. ${ }^{23}$

The current study focuses on hypersexuality in MSM and builds on earlier research exploring the role of affective processes, including sexual arousal. The study includes the measurement of the propensity for sexual excitation, ${ }^{25,26}$ but its principal aim was to test the relationship between hypersexuality and sexual responsivity at the state level, not at the trait level. That is, although sexual excitation (and to a lesser degree sexual inhibition) has been found to predict sexual response levels in the laboratory, ${ }^{27,28}$ and although it has been predictive of the selfregulation of sexual arousal in men with different levels of sexual compulsivity, ${ }^{29}$ the current study directly compared hypersexual and non-hypersexual MSM in their sexual responsivity in the laboratory.

A second aim of this study was to compare the effects of negative mood on sexual arousal in hypersexual and nonhypersexual MSM. Thus, in addition to assessing general differences in sexual responsivity, we also wanted to examine possible differences between hypersexual and non-hypersexual MSM in the degree to which negative mood might impact their sexual responsivity. Difficulties with emotion regulation have been suggested to be a risk factor for hypersexuality. ${ }^{23,30}$ Consistent with this, the DSM-5 proposal for hypersexual disorder included the recurring experience of sexual fantasies, urges, or behaviors in response to "dysphoric mood states" as one of its diagnostic criteria. ${ }^{30}$ Indeed, several studies have found a relationship between hypersexuality and anxiety and depressed mood. ${ }^{4,12,23,31,32}$ Also, studies have found that negative mood states, in particular anxiety and sadness, can be associated with an increase in sexual risk behaviors and increased numbers of sexual partners in the past year, lifetime one-night stands, and casual sex partners. ${ }^{31,33-35}$ Furthermore, and consistent with qualitative findings on the impact of negative mood on risky sexual behavior, Bancroft and Vukadinovic ${ }^{4}$ found that self-defined male "sex addicts" were much more likely than a control group of men to describe a pattern of acting out sexually when feeling sad or depressed. The authors proposed 3 pathways through which negative mood may lead to "out of control" sexual behavior: (i) as a means of seeking emotional support or validation; (ii) as a distraction from (sources of) negative affect; or (iii) through the co-occurrence of negative emotional states such as anxiety and sexual arousal. ${ }^{4,36}$ The 3 mechanisms have in common that sexual interest and arousal would not be as negatively impacted-and, in fact, may even be increased-by negative mood states in hypersexual individuals. The current study tested this assumption by inducing negative mood states (sadness and anxiety) in the laboratory and by comparing their impact on genital response and subjective sexual arousal in hypersexual and non-hypersexual MSM. We hypothesized that hypersexual MSM would show higher levels of genital response 
and subjective sexual arousal in response to sexual stimuli than non-hypersexual MSM. In addition, we predicted that sexual responses following negative mood inductions would be larger in hypersexual as compared to non-hypersexual MSM.

\section{METHODS}

\section{Participants}

Participants in this study were part of a larger project that included other tasks and measures. ${ }^{15} * \mathrm{MSM}$ were recruited using social media (eg, Facebook, Craigslist) and print materials were posted at and around a Midwestern University campus and in bars and nightclubs, sexual health clinics, and gay, lesbian, bisexual and transgendered and HIV service and community organizations in a large metropolitan area in the United States. Recruitment sites were selected in an effort to ensure the inclusion of a sufficient number of individuals who would meet the criteria for hypersexuality. Participants had to be male, at least 18 years old, to have had sex with other men at some point, and to have been sexually active within the past 90 days. Participants provided written informed consent and received a $\$ 100$ gift card at the end of the research session. All procedures were approved by the university's Committee for the Protection of Human Subjects.

Using an interview patterned after the Structured Clinical Interview for the DSM, participants were assigned to hypersexuality or control groups. ${ }^{\dagger}$ Hypersexuality criteria were operationalized consistent with definitions and methods used in previous research ${ }^{15,37-45}$ and included: (i) over a period of at least 6 months, experiencing recurrent intense sexual arousing fantasies, sexual urges, or behaviors involving 1 or more of the following: compulsive cruising and multiple partners; compulsive masturbation, including use of Internet pornography and cybersex, and/ or compulsive sex within a relationship ${ }^{\ddagger}$; (ii) the fantasies, sexual urges, or behaviors cause clinically significant distress, or impairment in social, occupational, or other important areas of functioning; and (iii) not due to another medical condition, such as substance abuse, or attributable to another psychiatric disorder such as mania, or a normal developmental stage. The interviews were conducted by 2 trained staff members. Audio recordings of the interviews were reviewed by the other interviewer and another research staff member. Discrepancies were resolved in consultation with 2 co-authors (N.R. and E.C.). Group assignment showed good inter-rater reliability $(\mathrm{K}=0.79)$.

\section{Questionnaires $^{5}$}

\section{Demographic and Background Questionnaire}

Variables assessed included age, race/ethnicity, education, and HIV status. At a later stage of the study-after recruitment had

\footnotetext{
* The order of tasks and measures was randomized across participants.

${ }^{\dagger}$ The interview schedule can be obtained by contacting the authors.

" The term "compulsive" was used during interviews as it helped convey the construct of hypersexuality to participants.
}

begun — questions were added about erotica use, including the number of erotic films/videos participants had viewed, how often they visited erotic websites, and how much money they spent to get access to erotic websites during "a typical month during the last year (eg, not on vacation or unusually busy)."

\section{Compulsive Sexual Behavior Inventory (CSBI-13) ${ }^{46}$}

This 13-item scale assesses impairment and/or distress associated with difficulty in controlling one's sexual feelings, urges, and behaviors. Participants rate each item on a 5-point scale ranging from 1 (never) to 5 (very frequently). The total scale score is computed by summing across items. The CSBI-13 has been shown to have adequate reliability, reliable criterion validity, and discriminant and convergent validity.

\section{Sexual Inhibition/Sexual Excitation Scales (SIS/SES) ${ }^{28,47}$}

The SIS/SES is a 45 -item instrument which measures the propensity for sexual excitation (SES), sexual inhibition due to the threat of performance failure (SIS1), and sexual inhibition due to the threat of performance consequences (SIS2).

\section{Beck Depression Inventory ${ }^{48}$}

This inventory is a 21 -item self-rating scale that assesses the severity of depressive symptoms. Scores can range from 0 to 63 , with higher scores indicating more severe depressive symptoms.

\section{Beck Anxiety Inventory 49}

This is a 21-item self-rating scale that assesses the severity of anxiety symptoms. Scores can range from 0 to 63 , with higher scores indicating more severe anxiety symptoms.

\section{Mood and Sexual Arousal}

Mood states were evaluated using the Positive and Negative Affect Schedule (PANAS) ${ }^{50}$ and the Mood and Anxiety Symptom Questionnaire. ${ }^{51}$ Each item of the 20-item PANAS asks about the current experience of a specific feeling and is graded on a scale from 1 (very slightly or not at all) to 5 (extremely). Scores on the positive and negative subscales can range from 10 to 50. The Mood and Anxiety Symptom Questionnaire includes a number of subscales to assess depressive, anxious, and mixed symptomatology, and it uses several items that are identical to those in PANAS. We used a selection of items that is also part of the PANAS to assess depressed (sum score of 6 items) and anxious mood (7 items).

Subjective sexual arousal was measured using 3 items, ${ }^{35}$ asking participants to indicate how sexually aroused, sexually interested, and horny they felt. Participants were asked to rate each item on a scale from 1 (not at all) to 5 (extremely). Scores on the subjective arousal measure could range from 3 to 15 .

\footnotetext{
${ }^{5}$ A number of questionnaire measures were used in this study which were not included in the current analyses.
} 


\section{Mood and Erotic Stimuli}

Neutral, sad, and anxious affective states were induced using excerpts of documentaries and commercial movies. The films were pretested in a pilot study using an independent sample of 21 men who were asked to rate a total of 9 videos (3 for each mood state), based on an initial selection of over 65 videos. ${ }^{52-54}$ On the basis of the pilot study, we selected an excerpt from the movie "Silence of the Lambs" (in which an Federal Bureau of Investigation agent tries, in a dark basement, to capture a serial murderer who is wearing infrared glasses) for the Anxious mood condition and a clip from "Sophie's Choice" (in which a prisoner in a concentration camp is forced to decide whether her daughter or son will be taken away from her) for the Depressed mood condition. The Neutral condition consisted of a scene from a nature documentary about ocean life. The 3 videos were 3 minutes in length. Erotic excerpts were taken from commercially available films used in previous research. ${ }^{55}$ The videos depicted consensual sexual interactions between 2 adult men, which progressed from petting to oral sex and anal intercourse. Additional neutral film excerpts were used for baseline (8 minutes) and return-to-baseline (3 minutes) intervals.

\section{Genital Responses}

Genital responses were measured using mercury-in-rubber penile strain gauges (D M Davis, Inc, Teaneck, NJ, USA). The gauges, which measure penile circumference, were calibrated at the start of each laboratory session using a set of rings of known circumference (in $\mathrm{mm}$ ). Participants were instructed to place the gauge toward the base of the penis. Physiological data were recorded using a Limestone system (Limestone Technologies, Inc, Ontario, Canada). Erectile responses were operationalized as difference scores ${ }^{56}$ and calculated by subtracting the average circumference recorded during the last minute of the prestimulus baseline period from the data obtained, and averaged at 10-second intervals, during the erotic film conditions. New penile gauges were used for each subject.

\section{Procedure}

After arriving for the experimental session at the psychophysiological laboratory and having provided informed consent, subjects were seated in a reclining chair in front of a monitor and, after careful instruction, asked to put the genital device in place. They signaled the experimenter, who was in the adjoining room, when they were ready to start via an intercom. Following an 8minute baseline period, during which a neutral film was presented, participants were presented with the mood films, each followed by an erotic video. Prior to and following each video presentation, participants completed questions and were presented with neutral film clips for the assessment of return-tobaseline levels. All participants were first presented with the neutral-erotic film combination to allow for a test of general responsivity while minimizing possible effects of repeated stimulus presentations (eg, carryover, habituation). The order of the negative mood inductions (anxious/depressed) was randomized within groups (see Figure 1).

\section{Analyses}

Genital responses (difference scores) were subjected to a mixed-model ANOVA using IBM SPSS Statistics 25 for Mac OS X (IBM Corporation, Armonk, NY, USA). The GreenhouseGeisser epsilon procedure was applied to correct for the violation of the sphericity assumption. ${ }^{57}$ All repeated measures ANOvA results are reported with uncorrected degrees of freedom, but with corrected $P$ values.

\section{RESULTS}

\section{Sample Characteristics}

A total of 242 men participated in the study; 93 men were assigned to the hypersexuality group and 149 men were controls. Due to technical problems and incomplete or missing data, 31 subjects were excluded, leaving the data of $211 \mathrm{men}$ for analysis (81 hypersexual men and 130 controls). The average age of the hypersexual men was 38.3 years $(\mathrm{SD}=10.2)$, and the average age of the men in the control group was 33.8 years $(\mathrm{SD}=12.7$; $\mathrm{t}(193.7)=2.83, P<.01)$. The majority of men in the 2 groups were white $(74 \%$ of the men in the control group and $78 \%$ of the hypersexual men, see Table 1). Also, almost half of the men assigned to the hypersexual group were $\mathrm{HIV}+$, as compared to $19 \%$ of the control group.

\section{Manipulation Check}

The self-reported mood following inductions indicates that our mood inductions were successful. Mixed-model ANOVAs revealed that mood ratings differed by condition (positive affect: $\mathrm{F}(2,418)=45.75, P<.001$, partial $\eta^{2}=0.18$; anxiety: $\mathrm{F}(2$, $418)=66.23, P<.001$, partial $\eta^{2}=0.24$; depressed mood: $\mathrm{F}(2,418)=198.79, P<.001$, partial $\left.\eta^{2}=0.49\right)$, but not by group (all $P>.1$ ). Self-reported positive affect was lower following the anxious $(\mathrm{t}(210)=6.66, P<.001)$ and depressed $(\mathrm{t}(210)=8.27, P<.001)$ mood inductions than following the neutral film. Self-reported anxiety was higher following the anxious induction than following the neutral $(\mathrm{t}(210)=10.13$, $P<.001)$ and depressed $(\mathrm{t}(210)=2.68, P<.01) \mathrm{mood}$ inductions. Self-reported depressed mood was significantly higher following the depressed than following the neutral $(\mathrm{t}(210)=15.64, P<.001)$ and anxious $(\mathrm{t}(210)=17.88$, $P<.001)$ mood inductions.

\section{Genital Response and Subjective Sexual Arousal}

A mixed-model (group: hypersexual/control $\times$ mood: neutral/ anxiety/depression $\times$ time: eighteen 10 -second intervals) ANOVA on the genital response data revealed significant main effects of group $(\mathrm{F}(1,209)=7.41, P<.01)$ and condition $(\mathrm{F}(2$, $418)=11.77, P<.001$, partial $\left.\eta^{2}=0.053\right)$. In addition, significant interactions of group $\times$ condition $(F(2,68)=3.98$, 


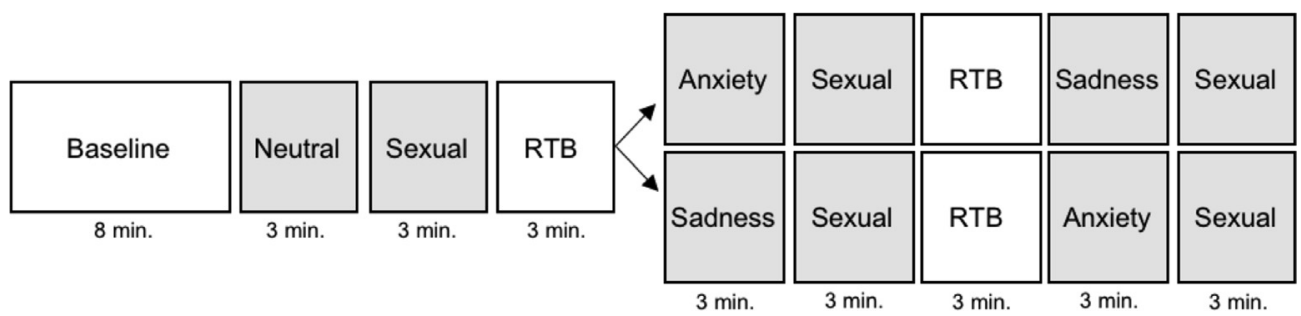

Figure 1. Study design. RTB = return to baseline.

$P<.04$, partial $\left.\eta^{2}=0.053\right)$ and group $\times$ condition $\times$ time $\left(\mathrm{F}(2,68)=3.98, P<.04\right.$, partial $\eta^{2}=0.053$; see Figure 2$)$ were found. Follow-up tests on the 3 -way interaction effect, by condition, revealed significant main effects of group-with the hypersexual group responding less strongly-for each of the 3 conditions and a significant interaction of group $\times$ time for the anxious mood condition $(\mathrm{F}(1,17)=4.88, P<.01$, partial $\left.\eta^{2}=0.023\right)$. Responses of the hypersexual group were significantly lower than those of the control group during the anxious mood condition, except for the first minute of the sexual film.

As the 2 groups significantly differed in age, we conducted an analysis of covariance with age as a covariate (correlations between age and mean genital response: $r=-0.39$ for neutral; $r=-0.40$ for anxiety; and $r=-0.42$ for depressed mood inductions). Also, because almost half of the men assigned to the hypersexual group were $\mathrm{HIV}+$, we added HIV status as a

Table 1. Sample demographic characteristics ( $N=211)$

\begin{tabular}{|c|c|c|}
\hline & $\begin{array}{l}\text { Hypersexual } \\
\text { group }(\mathrm{N}=81)\end{array}$ & $\begin{array}{l}\text { Control } \\
\text { group }(\mathrm{N}=130)\end{array}$ \\
\hline Age, mean (SD)* & $38.3(10.2)$ & 33.8 (12.7) \\
\hline $\begin{array}{l}\text { Years of } \\
\text { education, mean (SD) }\end{array}$ & $15.3(2.6)$ & $15.1(2.3)$ \\
\hline \multicolumn{3}{|l|}{ Race/ethnicity, \% } \\
\hline White & 78 & 74 \\
\hline African American & 8 & 11 \\
\hline Native American & 2 & 6 \\
\hline Asian/Pacific Islander & 4 & 1 \\
\hline Latino & 3 & 5 \\
\hline Other & 5 & 3 \\
\hline Steady partner, \% & 49.4 & 48.5 \\
\hline \multicolumn{3}{|l|}{ HIV status, ${ }^{\dagger} \%$} \\
\hline Positive & 46 & 19 \\
\hline Negative & 49 & 74 \\
\hline Unknown & 5 & 7 \\
\hline Alcohol use, mean (SD) & $1.7(1.4)$ & $2.0(1.2)$ \\
\hline Drug use, mean (SD) & $1.1(1.4)$ & $1.0(1.3)$ \\
\hline $\begin{array}{l}\text { Depression } \\
\text { (BDI), mean (SD)* }\end{array}$ & $12.4(6.8)$ & $10.4(6.8)$ \\
\hline Anxiety (BAI), mean (SD) & $9.5(7.3)$ & $7.9(7.0)$ \\
\hline
\end{tabular}

Alcohol use and drug use: 0 (never) to 4 ( 4 times a week or more). $\mathrm{BAI}=$ Beck Anxiety Inventory; BDI = Beck Depression Inventory.

*Groups different at $P<.05$.

${ }^{\dagger}$ Groups different at $P<.001$. between-subject factor. With age as covariate, none of the previously found main and interaction effects were significant (all $P>$.3). However, we did find a significant main effect of HIV status $(\mathrm{F}(1,205)=5.56, P<.02): \mathrm{HIV}+$ men (mean $[\mathrm{M}]=6.80$, standard error $=0.54)$ responded less strongly than HIV - men $(M=9.12$, standard error $=0.81)$.

We also ran a mixed-model (group: hypersexual/control $\times$ mood: neutral/anxiety/depression) ANOVA for subjective sexual arousal. This analysis revealed no significant main or interaction effects (all $P>.3$ ). An analysis of covariance with age as covariate (correlations with subjective sexual arousal: $r=-0.17$ for neutral; $\mathrm{r}=-0.22$ for anxiety; and $\mathrm{r}=-0.22$ for depressed mood inductions) and HIV status as a second between-group factor also revealed no significant main or interaction effects.

\section{Additional Analyses}

Response levels obtained in this study were variable and, as Figure 2 shows, in the low to medium range. Almost 55\% of all participants responded with less than $10 \mathrm{~mm}$ penile circumference change to the erotic film following the neutral mood induction. Approximately 33\% of men responded with less than $5 \mathrm{~mm}$ circumference change to this same condition. Therefore, we conducted a series of additional, exploratory analyses, using time series clustering, ${ }^{58}$ to examine if we could identify meaningful response trajectories. Time series clustering analysis offers an important advantage over repeated-measures ANOVAs and nonlinear regression approaches. The latter apply curve-fitting approaches, which are constrained in their assumptions about curve shape, whereas time series clustering relies on "distance" matrices. Distances can be calculated using various metrics, after which a distance matrix is used to identify which responses are closest in distance to each other. This means that any shape of the response curve that characterizes a group of participants can be captured, instead of limiting the range of shapes (eg, linear, quadratic) to those that are defined in advance.

We calculated dissimilarity between response trajectories using "unsupervised wavelet feature extraction". 58 Hierarchical clustering was used to create time series clusters, which were then tested using the TSclust library. ${ }^{59}$ One participant was excluded from the final analyses as he consistently failed to fit in any cluster. Using the data of the remaining subjects, we compared the fit solutions for 2-8 clusters. The 3-cluster solution fit the data significantly better than the 2-cluster solution, and a higher 
Hypersexual Group

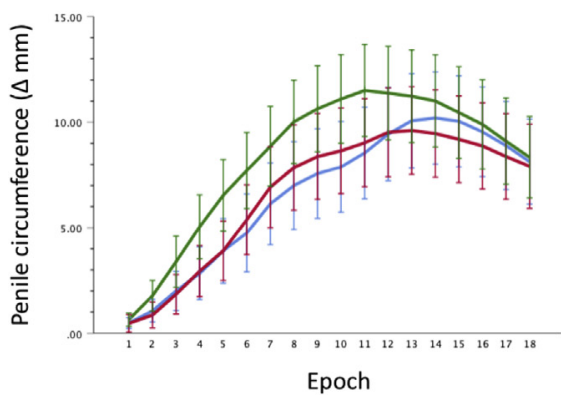

Control Group

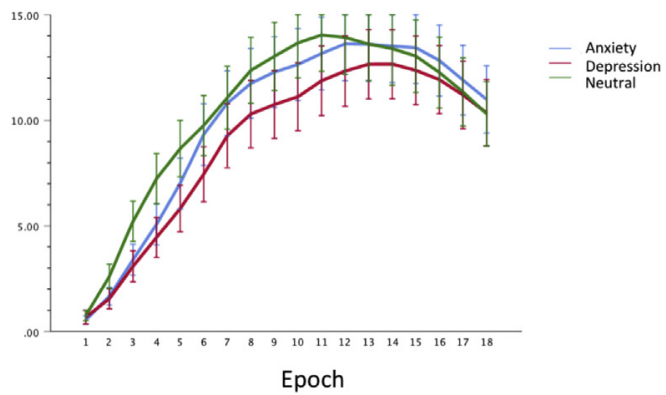

Figure 2. Genital responses to sexual films following anxiety, depression, and neutral mood inductions for control and hypersexual men. Figure 2 is available in color online at www.jsm.jsexmed.org.

number of clusters did not improve the fit further. Thus, the 3 cluster solution was retained. Figure 3 shows the response curves for each of the 3 clusters, which can be described as a strong response reaching the peak quickly $(\mathrm{N}=56$, cluster 1 : rapid and strong response), a strong response that is slower to peak $(\mathrm{N}=21$, cluster 2 : slow and strong response), and a smaller response with a variable, unclear peak $(\mathrm{N}=133$, cluster 3: low response). Using a leave-one-out fit test, this 3-cluster solution explained $96.2 \%$ of the variance.

We next explored whether these response patterns could be predicted by sexual excitation and inhibition, sexual compulsivity (CSBI-13), and pornography use (sum score of all items ${ }^{\|}$). Sexual excitation significantly predicted cluster membership $(\mathrm{F}(1$, $208)=8.9, P<.005$, partial $\left.\eta^{2}=0.04\right)$. Specifically, the rapid, strong response group scored the highest on sexual excitation $(\mathrm{M}=62.3, \mathrm{SD}=7.6)$, followed by the slow, strong response group $(\mathrm{M}=59.8, \mathrm{SD}=7.8)$ and the low response group $(\mathrm{M}=57.4, \quad \mathrm{SD}=7.8 ;$ Tukey honestly significant difference $=4.6, \mathrm{CI}=1.6-7.5, P<.001)$. None of the other variables predicted erectile response trajectories.

\section{DISCUSSION}

This study compared the sexual responsivity of hypersexual and non-hypersexual MSM in the laboratory. Controlling for age and HIV status, no differences in genital response were found between hypersexual and non-hypersexual men. Also, the 2 groups did not differ in subjective sexual arousal. An earlier study ${ }^{56}$ found that the MSM who scored high on a sexual compulsivity scale responded less strongly to sexual stimuli than MSM who scored low on this scale. In addition, genital response levels were negatively correlated with erotica use. In the current study, which included a substantially larger sample and which relied on the use of a diagnostic interview to assign men to hypersexual and non-hypersexual groups, we found relatively low response levels in both groups.
Individual response levels were predicted by sexual excitation (SES), but not by compulsive sexual behavior scores or pornography use. This finding is consistent with a growing body of research finding no association between pornography use and erectile function. ${ }^{60-67}$ Also, our results are consistent with those of Steele and colleagues, ${ }^{9}$ who found that measures of sexual desire, but not compulsive sexual behavior, predicted brain responses to erotic film. Similarly, Winters and colleagues, ${ }^{29}$ in a sample of mostly heterosexual men, found that compulsive sexual behavior did not predict the ability to self-regulate sexual arousal. However, sexual desire and sexual excitation and inhibition did [cf.]. ${ }^{68}$

We used time series clustering with wavelet feature extraction to examine differences among participants, not just in their levels of response but also in the shape of their response. These analyses revealed 3 clusters, one of which, the largest in number, could be described as involving low responders, with a peak that was not welldefined. The other 2 groups, both higher in overall response levels, mainly differed in the speed with which they reached their maximum response. The group of men who were the fastest to reach the higher levels of response scored the highest on the propensity for sexual excitation. Although these clusters were not predicted a priori, the differentiation between groups based on a combination of level and shape of response is relatively novel and could, we believe, prove to be a valuable analytical tool in other areas of sexual psychophysiology, including research on sexual dysfunction, especially when the goal is to detect or to test for differences between various (sub)groups.

A second aim of this study was to compare the effects of negative mood on sexual arousal in hypersexual and nonhypersexual MSM. More specifically, we wanted to test the assumption that sexual arousal might not be (as) negatively impacted and, in fact, could be increased by negative mood states in hypersexual individuals. Although the manipulation check supported the effectiveness of our sadness and anxiety inductions, we did not find any clear effects of negative mood on genital responses or subjective sexual arousal. Empirical 


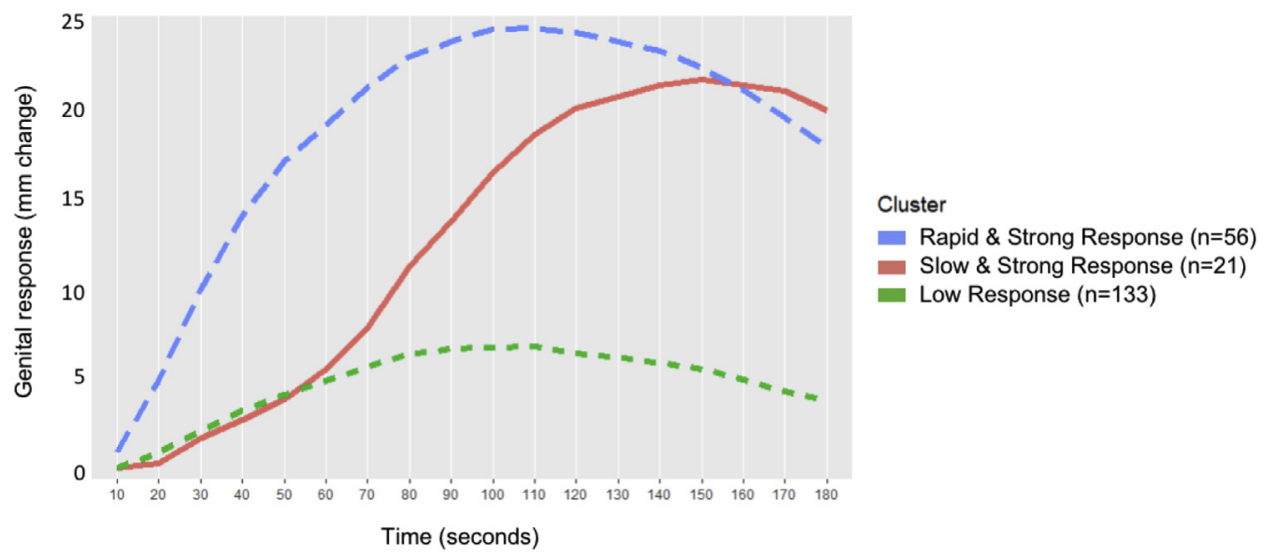

Figure 3. Penile response clusters. Figure 3 is available in color online at www.jsm.jsexmed.org.

literature on the relationship between mood and sexuality, and especially between mood and sexual arousal, is complex, ${ }^{69,70}$ with some studies reporting negative effects, ${ }^{71}$ no effects, ${ }^{72}$ or even positive effects ${ }^{73}$ of negative mood and emotions on men's sexual responses. Our finding that negative mood did not differentially impact sexual responses of hypersexual or non-hypersexual men is relevant, however, as it suggests that of the various mechanisms proposed by Bancroft and Vukadinovic, ${ }^{4}$ a possible compatibility between negative emotional states and sexual arousal is, in and of itself, not sufficient to explain the link between negative mood and "out of control" sexual behavior. Future studies could explore in more depth the impact of negative mood on motivational (including the experience of desire) and behavioral processes. In other words, given the lack of any clear effects of negative mood on sexual response in this study, it may be more fruitful to explore motivational and behavioral effects, including, for example, the impact of negative mood on the tendency to seek out sex for emotional support or validation or to distract oneself from (possible sources of) negative affect. ${ }^{4}$ Relevant to this suggestion, a recent study ${ }^{74}$ found a complex interaction effect of negative and positive affective arousal on engaging in partnered sexual behavior and masturbation/erotic stimuli use.

Another possible explanation is that we selected a general and heterogeneous sample of men meeting the criteria for hypersexuality and that, for some men, the mechanisms of negative mood impacting motivational and behavioral processes may be salient. There may be typologies of men with hypersexuality with different underlying mechanisms that are responsible.

Some limitations of this study should be acknowledged. First of all, we found relatively low response levels in both groups. More than half of all participants responded with less than $10 \mathrm{~mm}$ penile circumference change to the erotic film following the neutral mood induction. This may in part be attributed to this study's complex and heterogeneous sample. A large proportion of men were HIV+ and our analyses revealed that this was associated with lower response levels. It is unclear at this point what would be the most likely explanation for this, but it could involve a number of factors, including physical and mental health, medication use, etc. Also, although we have no reason to question the credibility of those participants indicating they were HIV+, HIV status was based on self-report, and future studies could include HIV tests for all participants. In addition, we only included men who indicated having sex with men, but as we did not require them to specify their sexual orientation, it is possible that some men might have become more aroused if other (eg, bisexual) stimuli would have been included. A related factor that could have played a role in this involves the fact the sexual stimuli were selected by the researchers. In a study on the association between sexual risk taking and psychophysiological response patterns in heterosexual and homosexual men, ${ }^{75}$ response levels were substantially higher when participants were allowed to select sexual film stimuli themselves. Future studies could consider combining the use of researcher- and self-selected sexual stimuli. Moreover, in general, we acknowledge the limitations of studying sexual arousal in a laboratory context, and it is possible that response levels would have been higher in a more natural (eg, home) setting. Furthermore, although our mood inductions proved to be successful, we lack information on how long these mood states were maintained. It is not uncommon to examine the effects of an emotional state by first inducing this state (eg, through film, music, or imagery) and then, at completion of the induction, to assess its effects on performance on a specific task or on some psychophysiological variable. However, most studies using this approach do not test for the duration of the mood effects. Future studies might benefit from the inclusion of physiological measures of affect (eg, corrugator electromyography), which would allow for a nonintrusive and continuing manipulation check. Another shortcoming of this study involves the fact that we added questions about pornography use at a later phase of the study, after recruitment had begun. Although this means that for the prediction of the different response clusters we did not have the same number of data points for sexual excitation, compulsive sexual behavior, and pornography use, we believe that we had a large enough number of observations $(\mathrm{N}=101)$ to allow for the detection of an association between sexual response and pornography use. Finally, hypersexuality was 
defined using criteria for compulsive sexual behavior, ${ }^{15,39,42}$ which require more clinical judgment than the criteria that were used in the DSM-5 field trials. ${ }^{32}$ Also, the final diagnosis, at the individual level, does not reflect or provide information on the relative weight of actual behavior (eg, in terms of frequency), and what these behaviors involve (eg, cruising, masturbation, porn use), vs the level of distress experienced by the individual. Future research could more systematically compare different (sub)groups, as sexual arousal patterns-which are typically assessed using visual erotic materials - may be more pronounced in and informative about underlying processes in some groups (eg, porn using) compared to other (eg, cruising, cybersex) groups.

\section{CONCLUSIONS}

This study assessed general sexual responsivity and the effects of negative mood on sexual arousal in hypersexual MSM. We did not find evidence for the notion that hypersexual men, as compared to non-hypersexual men, might show stronger responses to sexual stimuli in the laboratory. Also, we did not find any, general or differential, effects of negative mood on sexual arousal. However, we did find that sexual excitation predicted response levels. Combined, these findings suggest that future studies could focus more on motivational and behavioral processes and effects. In addition, research on the psychophysiology of hypersexuality might benefit from a more systematic comparison of potentially relevant subgroups, which vary in the type of behaviors involved (eg, pornography use vs partnered sex) and the degree of experienced distress.

\section{ACKNOWLEDGMENTS}

The authors would like to thank Cathy Ayers-Sobel, the project coordinator, and Ann Person, who conducted much of the data collection.

Corresponding Author: Erick Janssen, PhD, Institute for Family and Sexuality Studies, Department of Neurosciences, KU Leuven | University of Leuven, Campus St-Rafaël, Kapucijnenvoer 7, 3000 Leuven, Belgium. Tel: +32 163779 95; E-mail: erick.janssen@kuleuven.be

Conflict of Interest: The authors report no conflicts of interest.

Funding: Research reported in this publication was supported by the National Institute of Mental Health, National Institutes of Health, Award Number R01MH094229, M. Miner (principal investigator). The content is solely the responsibility of the authors and does not necessarily represent the official views of the National Institutes of Health.

\section{STATEMENT OF AUTHORSHIP}

\section{Category 1}

\section{(a) Conception and Design}

Erick Janssen; Michael H. Miner; Angus MacDonald, III; Nancy Raymond; Rebecca Swinburne Romine; Eli Coleman

\section{(b) Acquisition of Data}

Erick Janssen; Nicole Prause; Rebecca Swinburne Romine; Nancy Raymond; Angus MacDonald, III; Eli Coleman; Michael H. Miner

(c) Analysis and Interpretation of Data

Erick Janssen; Michael H. Miner; Nicole Prause; Angus MacDonald III; Nancy Raymond; Rebecca Swinburne Romine; Eli Coleman

\section{Category 2}

(a) Drafting the Article Erick Janssen

(b) Revising It for Intellectual Content Erick Janssen; Michael H. Miner; Nicole Prause; Angus MacDonald III; Nancy Raymond; Rebecca Swinburne Romine; Eli Coleman

\section{Category 3}

\section{(a) Final Approval of the Completed Article}

Erick Janssen; Michael H. Miner; Nicole Prause; Angus MacDonald III; Nancy Raymond; Rebecca Swinburne Romine; Eli Coleman

\section{REFERENCES}

1. World Health Organization. International classification of diseases for mortality and morbidity statistics (11th Revision). Available at: https://icd.who.int/browse17//-m/en\#/http\%3a\%2f \%2fid.who.int\%2ficd\%2fentity\%2f1630268048; $\quad$ Accessed June 18, 2020.

2. American Psychiatric Association. Diagnostic and Statistical Manual of Mental Disorders. Fifth Edition. Arlington, VA: American Psychiatric Association; 2013.

3. Kafka MP. What happened to hypersexual disorder. Arch Sex Behav 2014;43:1259-1261.

4. Bancroft J, Vukadinovic Z. Sexual addiction, sexual compulsivity, sexual impulsivity, or what? Toward a theoretical model. J Sex Res 2004; 41:225-234.

5. Coleman E, Dickenson J, Girard A, et al. An Integrative Biopsychosocial and Sex Positive Model of Understanding and Treatment of Impulsive/Compulsive Sexual Behavior. Sex Addict Compuls 2018;25:125-152.

6. Walton MT, Cantor JM, Bhullar N, et al. Hypersexuality: A Critical Review and Introduction to the "Sexhavior Cycle". Arch Sex Behav 2017;46:2231-2251.

7. Prause N, Steele VR, Staley C, et al. Modulation of late positive potentials by sexual images in problem users and controls inconsistent with "porn addiction". Biol Psychol 2015; 109:192-199.

8. Schmidt C, Morris LS, Kvamme TL, et al. Compulsive sexual behavior: Prefrontal and limbic volume and interactions. Hum Brain Mapp 2017;38:1182-1190.

9. Steele VR, Staley C, Fong T, et al. Sexual desire, not hypersexuality, is related to neurophysiological responses elicited by sexual images. Socioaffect Neurosci Psychol 2013;3:20770.

10. Voon V, Mole TB, Banca P, et al. Neural correlates of sexual cue reactivity in individuals with and without compulsive sexual behaviours. PLoS ONE 2014;9:e102419. 
11. Coleman E, Horvath KJ, Miner M, et al. Compulsive sexual behavior and risk for unsafe sex among internet using men who have sex with men. Arch Sex Behav 2010;39:1045-1053.

12. Parsons JT, Grov C, Golub SA. Sexual compulsivity, cooccurring psychosocial health problems, and HIV risk among gay and bisexual men: further evidence of a syndemic. Am J Public Health 2012;102:156-162.

13. Yoon IS, Houang ST, Hirshfield S, et al. Compulsive sexual behavior and HIVISTI risk: A review of current literature. Curr Addict Rep 2016;3:387-399.

14. Carvalho J, Stulhofer A, Vieira AL, et al. Hypersexuality and high sexual desire: exploring the structure of problematic sexuality. J Sex Med 2015;12:1356-1367.

15. Miner MH, Romine RS, Raymond N, et al. Understanding the Personality and Behavioral Mechanisms Defining Hypersexuality in Men Who Have Sex With Men. J Sex Med 2016; 13:1323-1331.

16. Seok JW, Sohn JH. Neural Substrates of Sexual Desire in Individuals with Problematic Hypersexual Behavior. Front Behav Neurosci 2015;9:321.

17. Štulhofer A, Bergeron S, Jurin T. Is High Sexual Desire a Risk for Women's Relationship and Sexual Well-Being. J Sex Res 2016;53:882-891.

18. Walton MT, Bhullar N. Hypersexuality, Higher Rates of Intercourse, Masturbation, Sexual Fantasy, and Early Sexual Interest Relate to Higher Sexual Excitation/Arousal. Arch Sex Behav 2018;47:2177-2183.

19. Hook JN, Hook JP, Davis DE, et al. Measuring sexual addiction and compulsivity: a critical review of instruments. J Sex Marital Ther 2010;36:227-260.

20. Muise A, Milhausen R, Cole $\mathrm{S}$, et al. Sexual Compulsivity in Heterosexual Married Adults: The Role of Sexual Excitation and Sexual Inhibition in Individuals not Considered "HighRisk". Sex Addict Compuls 2013;20:192-209.

21. Parsons JT, Rendina HJ, Ventuneac A, et al. Hypersexual, Sexually Compulsive, or Just Highly Sexually Active? Investigating Three Distinct Groups of Gay and Bisexual Men and Their Profiles of HIV-Related Sexual Risk. AIDS Behav 2016; 20:262-272.

22. Rettenberger M, Klein V, Briken P. The Relationship Between Hypersexual Behavior, Sexual Excitation, Sexual Inhibition, and Personality Traits. Arch Sex Behav 2016;45:219-233.

23. Walton MT, Cantor JM, Lykins AD. An Online Assessment of Personality, Psychological, and Sexuality Trait Variables Associated with Self-Reported Hypersexual Behavior. Arch Sex Behav 2017;46:721-733.

24. Winters J, Christoff K, Gorzalka BB. Dysregulated sexuality and high sexual desire: distinct constructs. Arch Sex Behav 2010;39:1029-1043.

25. Bancroft J, Janssen E. The dual control model of male sexual response: a theoretical approach to centrally mediated erectile dysfunction. Neurosci Biobehav Rev 2000;24:571-579.

26. Janssen E, Bancroft J. The Dual-Control Model: The role of sexual inhibition \& excitation in sexual arousal and behavior. In: Janssen E, ed. The Psychophysiology of Sex. Bloomington. IN: Indiana University Press; 2007. p. 197-222.
27. Hodgson B, Kukkonen TM, Binik YM, et al. Using the Dual Control Model to Investigate the Relationship Between Mood, Genital, and Self-Reported Sexual Arousal in Men and Women. J Sex Res 2016;53:979-993.

28. Janssen E, Vorst H, Finn P, et al. The Sexual Inhibition (SIS) and Sexual Excitation (SES) Scales: II. Predicting psychophysiological response pattens. J Sex Res 2002;39:127-132.

29. Winters J, Christoff K, Gorzalka BB. Conscious regulation of sexual arousal in men. J Sex Res 2009;46:330-343.

30. Kafka MP. Hypersexual disorder: a proposed diagnosis for DSM-V. Arch Sex Behav 2010;39:377-400.

31. Grov C, Parsons JT, Bimbi DS. Sexual compulsivity and sexual risk in gay and bisexual men. Arch Sex Behav 2010;39:940949.

32. Reid RC, Carpenter BN, Spackman M, et al. Alexithymia, emotional instability, and vulnerability to stress proneness in patients seeking help for hypersexual behavior. J Sex Marital Ther 2008;34:133-149.

33. Bancroft J, Janssen E, Strong D, et al. The Relation Between Mood and Sexuality in Gay Men. Arch Sex Behav 2003; $32: 231-242$.

34. Bancroft J, Janssen E, Strong D, et al. Sexual risk-taking in gay men: the relevance of sexual arousability, mood, and sensation seeking. Arch Sex Behav 2003;32:555-572.

35. Mustanski B. The influence of state and trait affect on HIV risk behaviors: a daily diary study of MSM. Health Psychol 2007; 26:618-626.

36. Jerome RC, Woods WJ, Moskowitz JT, et al. The Psychological Context of Sexual Compulsivity Among Men Who Have Sex with Men. AIDS Behav 2016;20:273-280.

37. Coleman $E$. Is your patient suffering from compulsive sexual behavior? Psychiatr Ann 1992;22:320-325.

38. Coleman E, Raymond N, McBean A. Assessment and treatment of compulsive sexual behavior. Minn Med 2003; 86:42-47.

39. Coleman E, Gratzer T, Nesvacil $L$, et al. Nefazodone and the treatment of nonparaphilic compulsive sexual behavior: a retrospective study. J Clin Psychiatry 2000;61:282-284.

40. Lloyd M, Raymond NC, Miner MH, et al. Borderline personality traits in individuals with compulsive sexual behavior. J Sex Addict Compuls 2007;14:187-206.

41. Miner MH, Raymond N, Mueller B, et al. Preliminary investigation of the impulsive and neuroanatomical characteristics of compulsive sexual behavior. Psychiatry Res 2009;174:146-151.

42. Raymond NC, Grant JE, Kim SW, et al. Treatment of compulsive sexual behavior with naltrexone and serotonin reuptake inhibitors: two case studies. Int Clin Psychopharmacol 2002;17:201-205.

43. Raymond NC, Coleman E, Miner MH. Psychiatric comorbidity and compulsive/impulsive traits in compulsive sexual behavior. Compr Psychiatry 2003;44:370-380.

44. Raymond NC, Lloyd M, Miner M, et al. Preliminary report on the development and validation of the Sexual Symptom 
Assessment Scale. Sex Addict Compulsivity 2007;14:119129.

45. Raymond NC, Grant JE, Coleman E. Augmentation with naltrexone to treat compulsive sexual behavior: a case series. Ann Clin Psychiatry 2010;22:56-62.

46. Coleman E, Swinburne Romine R, Dickenson J, et al. Compulsive sexual behavior inventory-13 (CSB-13). In: Milhausen RR, Sakaluk JK, Fisher TD, et al., eds. Handbook of sexuality-related measures. 4th ed. New York, NY: Routledge; 2019. p. 254-257.

47. Janssen E, Vorst H, Finn P, et al. The Sexual Inhibition (SIS) and Sexual Excitation (SES) Scales: I. Measuring sexual inhibition and excitation proneness in men. J Sex Res 2002; 39:114-126.

48. Beck AT, Ward $\mathrm{CH}$, Mendelson $\mathrm{M}$, et al. An inventory for measuring depression. Arch Gen Psychiatry 1961;4:561-571.

49. Beck AT, Steer RA. Beck anxiety inventory manual. San Antonio, TX: Psychological Corporation; 1993.

50. Watson D, Clark LA, Tellegen A. Development and validation of brief measures of positive and negative affect: the PANAS scales. J Pers Soc Psychol 1988;54:1063-1070.

51. Watson D, Clark LA. The mood and anxiety symptom questionnaire. Unpublished manuscript. lowa City: University of lowa, Department of Psychology; 1991.

52. Schotte DE, Cools J, McNally RJ. Film-induced negative affect triggers overeating in restrained eaters. J Abnorm Psychol 1990;99:317-320.

53. Gross J, Levenson R. Emotion elicitation using films. Cog Emot 1995;9:87-108.

54. Paradiso S, Robinson RG, Andreasen NC, et al. Emotional activation of limbic circuitry in elderly normal subjects in a PET study. Am J Psychiatry 1997;154:384-389.

55. Janssen E, Prause N. Sexual response. In: Cacioppo JT, Tassinary LG, Berntson GG, eds. Handbook of Psychophysiology. New York: Cambridge University Press; 2016. p. 284-299.

56. Janssen E, Hoffmann HL, Goodrich D, et al. The Effects of Alcohol on Self-Regulation of Sexual Arousal in Sexually Compulsive Men Who Have Sex with Men. Sex Addict Compulsivity 2016;23:313-323.

57. Vasey MW, Thayer JF. The continuing problem of false positives in repeated measures ANOVA in psychophysiology: a multivariate solution. Psychophysiology 1987;24:479-486.

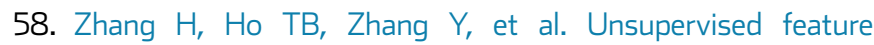
extraction for time series clustering using orthogonal wavelet transform. Informatica 2006;30:305-319.

59. Montero P, Vilar JA. TSclust: An R Package for Time Series Clustering. J Stat Softw 2014;62:1-43.
60. Berger JH, Kehoe JE, Doan AP, et al. Survey of Sexual Function and Pornography. Mil Med 2019;184:731-737.

61. De Graaf H, Wijsen C. Seksuele gezondheid in Nederland 2017. Sexual health in the Netherlands 2017. Leefstijlmonitor, Rutgers i.s.m. RIVM; 2017.

62. Grubbs JB, Gola M. Is Pornography Use Related to Erectile Functioning? Results From Cross-Sectional and Latent Growth Curve Analyses. J Sex Med 2019;16:111-125.

63. Klein $\mathrm{V}$, Jurin T, Briken P, et al. Erectile Dysfunction, Boredom, and Hypersexuality among Coupled Men from Two European Countries. J Sex Med 2015;12:2160-2167.

64. Landripet I, Štulhofer A. Is Pornography Use Associated with Sexual Difficulties and Dysfunctions among Younger Heterosexual Men. J Sex Med 2015;12:1136-1139.

65. Prause N, Pfaus J. Viewing Sexual Stimuli Associated with Greater Sexual Responsiveness, Not Erectile Dysfunction. Sex Med 2015;3:90-98.

66. Sutton KS, Stratton N, Pytyck J, et al. Patient Characteristics by Type of Hypersexuality Referral: A Quantitative Chart Review of 115 Consecutive Male Cases. J Sex Marital Ther 2015; 41:563-580.

67. Dwulit AD, Rzymski P. The Potential Associations of Pornography Use with Sexual Dysfunctions: An Integrative Literature Review of Observational Studies. J Clin Med 2019; 8:E914.

68. Moholy M, Prause N, Proudfit GH, et al. Sexual desire, not hypersexuality, predicts self-regulation of sexual arousal. Cogn Emot 2015;29:1505-1516.

69. Peterson ZD, Janssen E. Ambivalent affect and sexual response: the impact of co-occurring positive and negative emotions on subjective and physiological sexual responses to erotic stimuli. Arch Sex Behav 2007;36:793-807.

70. Janssen E. Sexual arousal in men: a review and conceptual analysis. Horm Behav 2011;59:708-716.

71. Mitchell WB, DiBartolo PM, Brown TA, et al. Effects of positive and negative mood on sexual arousal in sexually functional males. Arch Sex Behav 1998;27:197-207.

72. Nobre PJ, Wiegel M, Bach AK, et al. Determinants of sexual arousal and accuracy of its self-estimation in sexually functional males. J Sex Res 2004;41:363-371.

73. Cranston-Cuebas M, Barlow DH. Cognitive and Affective Contributions to Sexual Functioning. Ann Rev Sex Res 1990; 1:119-161.

74. Miner $\mathrm{MH}$, Dickenson J, Coleman E. Effects of Emotions on Sexual Behavior in Men with and without Hypersexuality. Sex Addict Compulsivity 2019;26:24-41.

75. Janssen E, McBride KR, Yarber W, et al. Factors that influence sexual arousal in men: a focus group study. Arch Sex Behav 2008;37:252-265. 